\title{
Opportunity and Choice: Concise Evaluation on Chinese Health System Reform
}

\author{
Yuzhao Chen ${ }^{1} \&$ Jie $\mathrm{Ma}^{1}$ \\ ${ }^{1}$ College of Humanities and Social Sciences, Nanjing University of Aeronautics \& Astronautics, Nanjing, China \\ Correspondence: Yuzhao Chen, College of Humanities and Social Sciences, Nanjing University of Aeronautics \& \\ Astronautics, Nanjing, China. E-mail: chenyuzhaoj@126.com
}

Received: December 24, 2016

Accepted: January 24, 2017 Online Published: April 27, 2017

doi:10.5539/par.v6n1p13

URL: http://dx.doi.org/10.5539/par.v6n1p13

\begin{abstract}
A research report published by Three Parties and Five Departments was released in Beijing, which is devoted to establishing a people-oriented integrated service model. Although it hasn't aroused strong repercussions., there is still an opportunity that Chinese medical and health system reform get the right direction. A retrospective study of reform since 1990s showed that the dedate still lies in the market-led or government-led, however, it does not grasp the root. The essence of medical and health system reform is to clarify the boundary between government and market, and brings out the best in them, that is, it should be conductive to both market and the government.
\end{abstract}

Keywords: health system reform, people-oriented, marketization, government

\section{Introduction}

What is the road map of Chinese health reform? Should it be pro-market or pro-government model? over the years, the heated debate revolving the question that the health reform should take the market-led road or the government-led one never end. Someone argues that China should take the government-dominated pattern in the health system. Certainly, it is a greatly different from the government-dominated pattern in the control economic period. while other people think that marketization should be the reform's orientation. The divisions in the thoughts partly contribute to the drastic shift in the reform practice. Guided by these thoughts with different preferences, Chinese health reform has experienced several pendulum swings between government-led and market-led system since 1978. The practices in China has proved that neither the of totalitarian government model in the command economy nor the over-marketization model in Lassie-Faire market economy works well. A mix system of government and market should be the direction of the future reform. However, which will be given to the priority, efficiency or equity, government or market, is still a problem.

In 2016, A study report jointly made by Chinese government and World Bank was released in Beijing, which is devoted to establishing a people-oriented integrated service model. The report gives the Chinese health reform an objective assessment, point out what it achieved and the future problem facing china. In addition, the report has given detailed police suggestion to the future reform. the study is made jointly by the three government ministries and two world organizes, therefore, we can conclude that the contents in the report reflect the multilateral consensus from different parties. There is no doubt that the agreement among parities will diminish the resistance during the reform. Does it mean the report with agreement from the academics and the government departments will put an end to the quarrel of government or market? Our answer is uncertain.

Actually, Throughout the years of practice, it has come to realize that the health system is not a thing of one or the other, government or market. Now there is a consensus that the health system should take a mix system of government and market. But how to clarify the boundary between the government and market is one of the most difficult problem to tackle. Besides, how to overcome the resistance from the interest group is a real problem. The basic consensus has achieved, but more details are waiting to define. more importantly, all details of the reform will affect the interest of the actors in the reform.

The article proceeds in four major sections. The first section made a brief review of the reform history. After that, we made a concise assessment to the reform. Thirdly, we concentrate on the joint study report by the Chinese government and World Bank, World Health Organization. The report means the common understanding of the reform has been reached. But how to turn the consensus into reality is still a problem. In the fifth section, the 
paper proposes that the essence of the medical and health system reform is to clarify the boundary between government and market.

\section{A Brief Review of the Reform Since 1978}

\subsection{Over-marketization from 1978 to 2003}

Some people assert that the complete marketization of medical and health system reform started in the 1990s when the marketization reform in all fields was deepen and carried out thoroughly. Actually, the marketization of the health system began with the reform and opening up since 1978.

In Maoist time, the government in central planning economic took the full responsibility of providing health service to the majority of the people, although there was a great different Health Insurance Schemes in rural and urban area. However, with the pro-market reforms in 1978, market liberalization began to spread to nearly all fields. And the health care system cannot be avoided. like other economic reform in other fields, a free-market model was also applied into the health care. The central government began to withdraw the fund from the health system and local governments pushed care providers into the market to make their living like an enterprise. It was convinced that the health system reform should be a part of the fully free market economic reform and the reformers should have the determination to push all the actors in the health system into free market. All the medical and health products should be traded in the market just like a common product.

Guided by these thoughts, the health system began to take all-around marketization. In the 1980s, the County Hospitals began to adopt the contract system; in 1990s, the policy of rural enterprises promoting medical institutions and organizing extra people establish medical institutions was promoted; in 2000, with the promotion of Reform of State-owned Enterprise's Property Right, selling hospitals became a fashion, Su Qian and Hai Cheng sold public hospitals, which pushed the medical and health system into the so-called "market".

After years of government exit, the consequence is serious. According to the National Statistical Yearbook, the national total health expense was 659.8 billion Yuan in 2003, accounting for 5.6\% of GDP. Among these, the government investment was only $17 \%$, and enterprises and companies were $27 \%$, and the out-of-pocket expense by residents were up to $56 \%$. It can be seen that the system was underfinanced for many years. Lack of government funding support and profit-seeking in the market make the health system was riddle with many problems. "You can have everything except illness, and nothing but money" becomes a grumble of common people. it vividly describes the current situation of the health system, that is, the status of difficult and expensive to access medical treatment.

\subsection{Changes since 2003}

When it comes to 2003, the comprehensive marketization reform in the health system was universally condemned. Especially the outbreaks of SARS make the whole country to reflect the over-marketization in the health system.

Liu Xinming, the Director of the Health Ministry Policies and Regulations, pointed out that marketization was not the direction of the reform; on July 28, 2003, the report made by the Development Center of the State Council pointed out that the reform was not successful.

the government did not stop at the criticism from the words and it began to take actions. the direction of market-oriented reform began to shift subtly in 2003, especially after the SARs. In 2003, the central government began to promote new rural cooperative medical system in rural areas and implementation of serious illness as a whole, namely "the new rural security", thus the difficulties of seeing a doctor and expensive expenses were relieved slightly. In 2004 and 2005, China has invested more than 30 billion Yuan to perfect the public health and disease control system, which was 20 times compared to the usual years. On the basis of the hot discussion on whether the reform was successful in 2005, the national new medical care reform was officially started in 2006. In 2009, the 11 ministries and departments formed the coordination group divided into four teams to carry on the special inspections in 200 provinces and cities. In December, the sixth Plenary Session of the 16th CPC Central Committee proposed to establish a basic health care system which covers both urban and rural residents as the goal of medical care reform policy. In 2007, commissioned by the coordination group, WHO, Peking University, Tsinghua University and other nine institutions established the design team of new medical reform. In 2008, the Opinions on Deepening the Medical and Health System Reform (consultation paper) was released to the public and sought advice widely, which was the results of negotiation of several parties. In 2009, the State Council Approved Opinions on Deepening the Medical and Health System Reform and 2009-2011 Deepening Medical and Health System Reform Plan and planned to add investment 850 billion Yuan within 3 years, and new round of the reform would be issued. In 2010, the Ministry of Health issued the Guidance on the Reform Pilots of 
Public Hospitals and set up 16 public hospitals as reformed pilot cities. In 2011, the State Council's Guidance on Further Strengthening the Construction of Doctor Teams in Rural Areas was issued and rural medical houses were included into the implementation scope of basic medicine system and new rural cooperative medical system. In the early of 2012, the Ministry of Health evaluated the pilot cities and experts believed the interest chain was not broken, which is a great difficulty of the reform. In 2013, the State Council put forward four major work of medical care reform. In 2014, Li Keqiang proposed the reform towards all-around and deep dimension in the government work report and the State Council issued the Main Tasks of Deepening Medical and Health System Reform in 2014, and public hospitals became the key of the reform. In July of 2016, Chinese government worked with the World's Bank and WHO to carry out the integrated research on Chinese heath system to deepen the reform. In 2015, the fifth Plenary Session of the 18th CPC Central Committee raised the national strategy and took the improvement of nation's health as the main strategic objectives of health system.

\section{Accomplishments and Challenges}

\subsection{Accomplishments}

Corresponding to all these policy changes, the budget of the health system is changing. From the beginning of 2003, the investment proportion of Chinese government in the total health expenditure continued to increase, grew over $17 \%$ in 2009 , which meant the decline in the proportion of personal burden, decreased from $60 \%$ in 2001 to $31 \%$ in 2014 , but the benefiting degree of rural residents was different. Since 2008, the increase in the total cost of Chinese health growth was higher than the growth speed of GDP, the proportion of each health expenditure in GDP increased yearly. The proportion in GDP was $5.1 \%$ in $2012,5.6 \%$ in 2013 , less than $6 \%$ in 2015. The proportion of financial investment in the health sector in the whole financial investment continued to grow. The proportion was $4.57 \%$ in 2008 , rose to $5.35 \%$ in 2011 . According to the plan of new medical care reform, from 2009 to 2011, the government planned to increase 850 billion Yuan, but the actual investment was up to 1400 billion Yuan.

Continually increased funding has yield fruits. The huge financial investment has brought several good results. China has invested a lot in health infrastructure, accomplished full-range coverage of medical insurance, promoted the equalization of basic public health services, and established the basic drug system, which improved the accessibility and fairness of medical and health services greatly reduced the mortality of children and pregnant women and the incidence rate of infectious diseases, and significantly improved the health level of China residents and life expectancy. In 2015, the average life expectancy of Chinese residents increased 1.51 years old and reached 76.34 years and the overall level of people's health reached the average of middle-income countries. The less investment achieved higher healthy performance, which has won wide acclaims from the international community."

\subsection{Challenges}

Through strengthening the financial investment of government, the new reform improved the health level of residents and alleviated many social contradictions to some degree. However, there were some non-sustainable problems at the same time:

(1) In the past few years, the total health expenditure showed fast growth tendency. Though it seemed like the result of change of value and ideas, in fact the root lies in double-digit continued growth of market economy in China during the past decades. With global economic slowdown and adjusted economic structure, the growth of Chinese economy gradually slowed down. Undoubtedly, the rising health expenditure demand will be hard. According to the existing health expenditure, the total Chinese health cost in GDP will rise up to $9 \%$ in 2035 from $5.6 \%$ in 2014, and the average annual growth rate is $8.4 \%$. In the next 40 years, the total expenditure of health cost will be increased 3 times of the current level, which are obviously difficult to bear for national economy and finance.

(2) China is facing new challenges in meeting people's needs of national health care, especially the burns of rapid aging and chronic non communicable diseases. There are 1400 million people over 65 years old in China, and the number in 2030 will reach 2300 million. Chronic disease has become the top health threat in China, accounting for $80 \%$ of 10.3 million deaths each year.

Besides, aging and economic condition is a matter of urgency that must be considered seriously. as the joint report said, with the aging population in China and economic slowdown, the reform needs to make strategic changes. Otherwise, the future of the fiscal sustainability would be bleak. China's actual medical and health expenditures are expected to increase from 3500 billion Yuan in 2014 to 15800 billion Yuan in 2035, which will be a huge financial burden. 


\section{Common Understanding of the Reform}

How to accept these challenges? The joint report in 2016 gave some answers. On July 22, 2016, a research report conducted jointly by Three Parties and Five Departments (the World Bank, WHO and the Ministry of Finance $f$ China, the National Health and Family Planning Commission, the Ministry of Human Resources and Social Security), Deepening Health Reform in China, Building High-Quality And Value-Based Service Delivery was issued in Beijing.

The joint report pointed out that China has formed the medical service system based on hospitals, which emphasizes treatment but ignores prevention, focuses on service quantity instead of treatment service, and doesn't protect health from the source. Therefore, future medical and health system should turn to people-oriented, focus on enhancing grass-roots service quality and establish a medical and health service system with a high value.

The report had unprecedented influence for its boarder involving aspects as well as long duration. It was called "reform report in the highest level", and Zhang Shuo, the senior health expert from the World's Bank, and the main coordinator of this reform described it as "unparalleled". Interestingly, compared with the heated debate in 2007, the joint report received less responses. the Debate on market-led or government-led in 2017 was discussed fiercely and most relevant scholars were deeply involved. However, just as the influential media in China, Southern Weekend said, the responses of the academic circle to the medical reform report with highest order in the history was unexpectedly strong, even chilly. Zhang Shuo in his interview said that this report was not harsh.

The reason why this report can gain agreements from different parities lies in the balance in interest orientation, namely a balanced point that all parties can accept. Apparently, different parties have different interests. The view of the government and the scholar would be different, and even within the government there would be disagreement among ministries due to the different interest. To achieve consensus, there must be a compromise. in some ways, the publish of the report can be viewed as the common understanding of the reform.

Consensus at least means that China have a great opportunity in deepening the reform of the health care system. The next question is how to deepen the reform. The remedy given by the President of the World's Bank is to provide high-quality care at a reasonable price by the in-depth reform, in order to reduce the operation, cost of health care system. The remedy has been given, but how the remedy can be transformed into reality and enabling the reform to walk on the right track?

\section{Future Choices}

Through the years, guided by the pro-market or pro-government thoughts, the pendulum of practices has proved that market and government both have failures. The reform is not an either government or market choice. Both government and market are vehicles to achieve the reform goals. It has come to the consensus that a mix system of government and market approach would be the right direction of the reform.

This paper holds that the government-led or market-let dispute in Chinese medical and health system reform failed to seize the essence of problem, and the essence is to sort out the boundary between government and market. It is said that medical and health system is one system, including medical service, drug supply, health and epidemic prevention, but they are different in nature. Some public goods like sanitary and anti-epidemic, p0tential public goods medical services, and special medical services and health care products should belong to private goods. Due to different attributes, they belong to different categories of government and the market. The medical care reform in 1980s copied the contracting system and contracting worked. As for the policies issued later was to unburden by the name of reform so as to alleviate the financial burden of the government. It developed to the extreme. Qiu He Phenomenon that it was OK by selling hospitals. From 1998 to 2009, there were two launched reforms, although the reform in 2009 started the road that medical institutions turned to public welfare, but the contradiction between supply and demand has not been aliveated. What made people confused was the number of China grade- 2 and grade- 3 hospitals from 2002 to 2013 rose $29 \%$ and $82 \%$, and the beds in hospitals grew to 4.58 million one in 2013 from the 2.17 million on in 2000 , which more than doubled according to reports. Obviously, China's medical and health system is an operation system with low efficiency. As Zhu Hengpeng, the Director of the Public Policy Research Center of the Chinese Academy of Social Sciences pointed out: issues depended on financial investment is over, but the new mechanism has not been established. The authoritative Journal said more bluntly that the marketization of public hospitals is opposite to socialism.

A retrospective study of thoughts on medical care reforms since 1980s reveals that some people stressed market or government, among which some voices are from the perspective of ideology. In fact, the disputes and 
disagreement on medical care are superficial, and some scholars want to discuss from the basic characteristics of medical services. To sum up, the reform in 1980s is a kind of ignorance exploration in an extremely blind state; the behind is the government-led and market-led dispute, which impressed people with the feeling of one-sided viewpoint, and the ideology factor is involved. What's worse, some hospitals were sold out in a sense. The action of Qiu He was only a political speculation, and had nothing to do with reform. Interestingly, while the government and market dispute has not been settled, a report on Southern Weekend pointed out that the policy orientation has turned to marketization quietly. The background was the speech made by Li Keqiang in executive meeting of State Council on August 27, 2014. In his view, government and market should be used jointed in the reform. Chinese medical and health reform should be conductive to market and government because of the basic characteristics of medical services. The so-called market failure and government failure of reform are not exact evaluations. An effective reform should solve the following two questions: what kind of government investment is and what kind of medical marketization is.

In fact, since 1990s, some people hold that the reform is not only a professional problem, but also an economic problem essentially. However, this research points out that it is a social problem to some extent, such as treating minor diseases with the way of serious diseases, excessive medical treatment, medical disputes and unreasonable medical treatment system. Only relying on the reform cannot solve the problems fundamentally, that is to say, the medical and health system is a subsystem of the social system, and is closely related to the social system. For example, from the social distribution mechanism and distribution of medical and health resources, the disadvantages are known, and the reform can greatly reduce the operating expenses of China's health care system. To solve this problem in the boundary between government and market, the difficulty is not big. Some scholars believe that it cannot ignore the guidance significance of existing theories to raise the real debate to the level of theoretical thought. Indeed, just as Kenneth Arrow said in the Uncertainty and Welfare Economics of Health Care, the products of medical care exhibit the mixed nature of public goods and private goods. Consequently, the health system in most countries is a mix of public and private. However, what is superiority, government-oriented or market oriented? Different countries have different choices. It depends on the many factors, ideology and historical institutional arrangement and others.

As far as the future choices of Chinese health system, on one hand, government needs to carefully consider the eight suggestions in the joint research report by Chinese government and the world organizations in 2016; On the other hand, government should sort out the factors to block the reform which is not in the research report. The reason is that the development of Chinese medical and health system has the same difficulties with foreign countries and also has its own hardship and difficulties.

\section{Conclusion}

After oscillating between the government and the market model, Chinese heath system has come to a consensus that it should take a mix system of government and market. However, in many defined field, how to clarify the boundary between government and market is a challenging work. From remedy to reality, there is a long way to go and many obstacles to overcome. Most importantly, international experience is very valuable but cannot be transplanted easily, because Health system is a complex system which not only involves economic factors, but also involves sociologic factors and political factors. Especially, ideological component plays an important role. Therefore, Chinese heath system have to find out its own way through trial and error, just as many other reforms in China.

The orientation of the reform is very clear, that is ,to build a people-oriented integrated service model. To achieve the aim, the next step for Chinese health system reform is to make the optimal combination of government and market methods to reduce the cost and increase the availability of the medical and heath service and product. the reform should further utilize market mechanism to give "right incentive" to actors. At the same time, the government should take full responsibility in providing public goods but deregulation or even exit from the fields of private goods.

\section{References}

Blumenthal, D., \& Hsiao, W. (2005). Privatization and its discontents - the evolving Chinese health care system.

Brinkerhoff, D. W., \& Bossert, T. J. (2014). Health governance: principal-agent linkages and health system strengthening. Health Policy and Planning, 29(6), 685-693. https://doi.org/10.1093/heapol/czs132

Cai, H. Q. (2016). Unprecedented China health care reform report. Southern Weekend, August 4, 2016.

Daemmrich, A. (2013). The political economy of healthcare reform in China: negotiating public and private. Springer Plus, 2(1), 448. https://doi.org/10.1186/2193-1801-2-448 
$\mathrm{Hu}$, S. et al. (2008). Reform of how health care is paid for in China: challenges and opportunities. The Lancet, 372(9652), 1846-1853. https://doi.org/10.1016/S0140-6736(08)61368-9

Jiang, D. C., Wu, S. L., \& Wei, Y. C. (2015). Did the Chinese New Health System Reform Relieve the High Healthcare Cost? Public Administrative Comment, (5), 4-29.

Na, F. D. (2015). The Time to Deep Medical Care Reform: Sanming Mode. Qiu Shi, (7), 34-36.

Transformation of New Medical Reform: Open the Market by Liu Wei on Southern Weekend, 2014-10-9.

Wagstaff, A. et al. (2009). China's health system and its reform: a review of recent studies. Health economics, 18(S2). https://doi.org/10.1002/hec.1518

World Health Organization. Deepening Health Reform in China. (2016). Retrieved from www.wpro.who.int/china/publications/health-reform-in-china.pdf?ua $=1$

Yip, W., \& Hsiao, W. (2009). China's health care reform: A tentative assessment. China economic review, 20(4), 613-619. https://doi.org/10.1016/j.chieco.2009.08.003

Yip, W., \& Hsiao, W. C. (2015). What Drove the Cycles of Chinese Health System Reforms? Health Systems \& Reform, 1(1), 52-61. https://doi.org/10.4161/23288604.2014.995005

Zhuang, Y. Q. (n.d.). Supporting a comprehensive well-off society with the whole people's health. Retrieved from http://health.people.com.cn/GB/n1/2016/0822/c398004-28654714.html

\section{Copyrights}

Copyright for this article is retained by the author(s), with first publication rights granted to the journal.

This is an open-access article distributed under the terms and conditions of the Creative Commons Attribution license (http://creativecommons.org/licenses/by/4.0/). 